\title{
The current state of digitalization: Digital Native, Digital Immigrant and Digital Settler
}

\author{
Adile Aşkım KURT ${ }^{*}$ Selim GÜNÜÇ ${ }^{* *} \quad$ Mehmet ERSOY $^{* * *}$
}

\begin{abstract}
. $21^{\text {th }}$ century education lives a digital divide from many aspects in the view of learner and teacher characteristics. We face with digital natives who born to a digital culture and differ from digital immigrants of industrial age. On the other hand, a new group, digital settlers rise with different behaviour and attitude characteristics by the use of technology to keep up with the times. It is quite important to determine the aformentioned groups in this digital divide world and promoting digital immigrants to acquire characteristics of digital natives in order to reduce the conreoversy between them. In this direction this study purposes to draw attention to digital native and digital immigrant characteristics, reflections to learning and teaching experiences and also the concept "digital settler".
\end{abstract}

Keywords: Digital native, digital immigrant, digital settler, digital divide.

\footnotetext{
* Assoc. Prof. Dr., Anadolu University, Faculty of Education, Computer Education and Instructional Technology, Eskisehir, Turkey, E-mail: aakurt@anadolu.edu.tr

Ress. Assist., Anadolu University, Faculty of Education, Computer Education and Instructional Technology, Eskisehir, Turkey. E-mail: selimgunuc@hotmail.com

${ }^{* * *}$ Ress. Assist., Osmangazi University, Faculty of Education, Computer Education and Instructional Technology, Eskisehir, Turkey, E-mail: mehmetersoy@ogu.edu.tr
} 


\section{SUMMARY}

Introduction: Today, in this age of intensive digital division, it is important to determine these groups well and to take necessary precautions especially in educational environments. In this way, the digital native characteristics owned by digital immigrants and digital settlers will minimize the disagreement and lack of communication between the learner and teacher in educational environments. In this respect, in the present study, the reflections of the digital native and digital immigrant characteristics into learning-teaching experiences are discussed with the concept of digital settler.

Digital Native, Digital Immigrant and Digital Settler: Marc Prensky, who first introduced the concepts of digital native and digital immigrant, emphasized the importance of reconsidering education both for future and for the past. Prensky (2001) states that learners have changed radically in recent years; that they do not share the profile of a learner involved in the education system; and that they are "native speakers" of the digital language of the Internet, computers and video games. It is pointed out that although those in the position of a teacher were not born in the digital world, they have benefitted from new technologies in their lives and thus they are "digital immigrants". In this respect, it is reported that it would be beneficial to take sharers into consideration with respect to the dimensions of system, teacher and learner.

The group which is not digital native but has to follow the technology in order to keep up with the age could be defined as digital immigrant. Digital immigrants are individuals who were not born exactly in the technology age but who sometimes use. Digital immigrant represent parents who want to speak the same language with their children and to understand them better and sometimes refer to teachers supposed to use technology as well as to digital native learners. Digital immigrants could be said to include teachers, academicians, engineers and other individuals in business life, who are all supposed to use technology as required by their profession or by their job. Digital immigrant is neither as knowledgeable about technology and about its use as digital natives nor as away from it as digital settlers are. This new group of today's changing world comes up with different learning and also teaching characteristics due to their teacher roles. Digital settlers were defined by Odabaş1 (2009) and Palfrey and Gasser (2008). One can say they are slower than digital natives and digital immigrants, and accustomed to text-based learning and teaching. The other characteristics of digital settlers are being interested in a traditional and analog world, being relax in a 
isolated network and also information-centred working rather than taking role in action based efforts (Palfrey and Gasser, 2008; Prensky, 2005; Prensky, 2009; Shah and Jansen, 2011; Weiß and Bader, 2010; Weltevrede, 2011).

Digital Native and Digital Immigrant Characteristics: Today, understanding how digital natives learn and what their preferences are will contribute significantly to the education process. Undesirable situations in which learners criticize teachers negatively and vice versa are the result of mutual disagreement. For example, it is emphasized that in traditional classroom settings, learners represent digital natives and that teachers represent digital immigrants (Naish, 2008). One of the sources of this representative disagreement could be said to result from the fact that teachers and learners are educated in different educational systems.

It could be stated that digital natives can acquire different knowledge and skills more easily by using information technologies. Therefore, it is believed that digital natives have learning preferences and styles different from those of the previous generation (Bennett, Maton and Kervin, 2008; Dede, 2005). Digital natives use technology for learning activities and especially for social-communication purposes (Lei, 2009). Digital natives adapt themselves easily to new technologies and do not avoid using them because they learn how to use these technologies in a shorter time (Bennett, Maton and Kervin, 2008). Digital immigrants and especially digital settlers are afraid of damaging new technologies, yet digital natives know that everything can be restored by restarting the technological device. Thus, digital natives use technology without any fear (Günther, 2007; Rikhye, Cook, and Berge, 2009).

Discussion and Conclusion: Based on the results of studies conducted, it cannot be stated that the life styles of digital natives and their learning characteristics have not been understood completely. Considering the fact that most studies have been carried out by digital immigrants, it seems difficult to give meaning to digital natives' responses to events and people around them. It is thought that it is necessary to reconsider the problems likely to be experienced by teachers, parents, adolescents and adult learners in technology addiction, inappropriate use of technology and use of technology for an excessive amount of time. In a study carried out by McNeely (2005), the researcher stated that learners should consider technology as a tool. However, considering the fact that individuals of the new generation live with technology and that they usually use technological 
devices in their lives, it could be stated that for digital natives, technology is more than a device.

The claim that digital natives mentioned by researchers such as Gibson, Koontz, and Van Den Hende (2008) and Prensky (2001) were born in 1980s and the fact that this generation is considered as digital native are not supported by studies satisfactorily. It could be stated that individuals of this generation are digital natives but that not all of them show all the characteristics of digital natives. Therefore, it would be beneficial to redefine digital native individuals and to carry out studies on individuals born in 1990s. In addition, a long period of time has passed since Prensky (2001) explained the concept of digital natives; thus, it could be stated that it would be necessary to redefine the concepts of digital native and digital immigrant. It is necessary to conduct studies based on reconsidering not only these concepts but also learning styles and similar concepts related to digital natives (Dede, 2005).

In terms of the concept of future-centered education, the new world order has made it necessary to train individuals who can process information effectively. Learners have certain expectations from technology as well as from universities in terms of use of current technologies in learning processes. That is, if the goal is to train a generation saying "the school did not teach me anything, I learnt everything from games" (Prensky, 2005), then it is undoubtedly necessary to avoid certain traditions. 


\title{
Dijitalleşmede Son Durum: Dijital Yerli, Dijital Göçmen ve Dijital Göçebe
}

\author{
Adile Aşkım KURT ${ }^{*} \quad$ Selim GÜNÜÇ ${ }^{* *} \quad$ Mehmet ERSOY $^{* * *}$
}

ÖZ. 21. yüzyılda eğitim, gerek öğrenci gerekse öğretmen boyutunda dijital bir bölünmeyi yaşamaktadır. Endüstriyel çağın öğrencileri olan "dijital göçmenler” den birçok anlamda farklılıklar gösteren ve dijital kültür içinde doğan "dijital yerliler" ile daha çok karşı karşıyayız. Öte yandan, son yıllarda teknolojiyi bir anlamda çağın gerisinde kalmamak amacıyla geçici ya da zorunlu olarak kullanan yeni bir grup olan "dijital göçebeler" dijital çağdaki varlıklarını sürdürmeye çalışmaktadır. Dijital bölünmenin yoğun olarak yaşandığı günümüzde sözü edilen grupların sağlıklı biçimde tanımlanarak özelikle eğitim ortamlarında gerekli önlemlerin alınması önem taşımaktadır. Böylelikle, dijital göçebelerin ve göçmenlerin dijital yerli özelliklerini belli ölçüde taşımalarının sağlanması eğitim ortamlarındaki öğrenci-öğretmen arasındaki anlaşmazlığı ve iletişim eksikliğini en az düzeye indirebilecektir. Bu bağlamda çalışmada, dijital yerli ve dijital göçmen özelliklerinin öğretme-öğrenme yaşantılarına yansımaları dijital göçebelik kavramı eşliğinde ele alınmıştır.

Anahtar Sözcükler: Dijital yerli, dijital göçmen, dijital göçebe, dijital uçurum, dijital bölünme.

\footnotetext{
* Doç. Dr., Anadolu Üniversitesi Eğitim Fakültesi Bilgisayar ve Öğretim Teknolojileri Eğitimi Bölümü Eskișehir, Türkiye. E-posta: aakurt@anadolu.edu.tr

** Arş. Gör., Anadolu Üniversitesi Eğitim Fakültesi Bilgisayar ve Öğretim Teknolojileri Eğitimi Bölümü Eskişehir, Türkiye. E-posta: selimgunuc@hotmail.com

*** Arş. Gör., Osmangazi Üniversitesi Eğitim Fakültesi Bilgisayar ve Öğretim Teknolojileri Eğitimi Bölümü Eskişehir, Türkiye. E-posta: mehmetersoy@ogu.edu.tr
} 


\section{GíRiș}

Son yıllarda toplumların bilişim teknolojilerini kullanma ve bundan fayda sağlama adına ciddi bir yarış içinde olduğu görülmektedir. En yaygın bilişim teknolojileri arasinda yer alan bilgisayar, internet, cep telefonu gibi teknolojilerin üretimi ve kullanımı toplumların gelişmişliğinin önemli göstergeleri olarak kabul edilmektedir (Huang, Keser, Leland ve Shachat, 2003). Toplumlar, bireylerinin bu teknolojilere sahip olmaları ve erişebilmeleri için çaba sarf ederken bu çabada başarılı olan toplumlar ile başarısız olan toplumlar arasında bir fark oluşmaktadır. Teknolojinin etkisiyle toplumlar arasında meydana gelen ayrım; dijital bölünme, sayısal uçurum, sayısal bölünme, sayısal kopma gibi farklı kavramlarla ifade edilen dijital uçurumdur. Dijital uçurum, farklı sosyo-ekonomik düzeyde yer alan bireylerin, kurumların ya da toplumların bilişim teknolojilerine erişimindeki ya da kullanımındaki eşitsizliği ifade etmektedir. Aynı zamanda bu kavram; bilişim teknolojilerine erişebilen ve etkin biçimde kullanabilenler ile bunu yapamayanlar arasındaki farka da işaret etmektedir (Büyüktanır, Duke, Karasar, Tileylioğlu ve Toth, 2006). Dijital uçurumun belirlenmesinde birçok gösterge kullanılabilirken son yıllarda yapılan araştırmalarda özellikle bilgisayar, cep telefonu, internet erişimi ve kullanımının en çok dikkate alınan göstergeler olduğu gözlenmektedir (Coyle, 2007; Goldfarb ve Prince, 2008; Hassani, 2006; Helsper ve Livingstone, 2007; Prieger ve Hu, 2008). Dijital uçurum sadece bireyler, kurumlar ve toplumlar arasında değil, aynı zamanda nesiller arasında da kendini göstermektedir. Nesiller arasındaki teknolojiden ve teknoloji kullanımından kaynaklanan bu farklılık dijital yerli ve dijital göçmen kavramlarıyla ifade edilmektedir. Bu çalışmada, dijital yerli ve dijital göçmen kavramları ele alınmış, dijital yerli ve dijital göçmenlerin tercihleri ve özelliklerindeki farklılıklar alanyazın çerçevesinde incelenmiş ve henüz yeni bir kavram olan dijital göçebe kavramı açıklanmaya çalışılmıştır.

\section{Dijital Yerli, Dijital Göçmen ve Dijital Göçebe}

Günümüz dünyasında her geçen gün etkisini daha fazla hissettiren bilgi alışverişi trafiğgi, kendini ifade etmek için elinden geleni yapan bir neslin söz sahibi olduğunu göstermektedir. İnsanoğlu yeni kimliği ile bir anlamda içgüdüsel olarak eğik ve yokuşlu bir yol yerine, dümdüz bir yolu kullanarak bilgiye erişmeye yönelmiş durumdadır. Büyük çoğunluğu çevrimiçi bireylerden oluşan dijital nesil beraberinde farklı bir yerleşik topluluğun da temellerini atmıştır. Zamanının çoğunu internette ve diğer teknolojileri kullanarak geçiren bu yeni topluluk farklı araştırmacılar tarafindan; yeni bin 
y1lın öğrencileri (Pedro, 2006), Y nesli (McCrindle, 2006), internet nesli (Oblinger ve Oblinger, 2005), teknolojik yerli (Monereo, 2004), dijital yerli (Prensky, 2001) gibi farklı ama benzer kavramlarla ifade edilmiştir. Bunlar arasında en dikkat çeken kavramlar Prensky (2001) tarafından ifade edilen "dijital yerli" ve "dijital göçmen" kavramlarıdır.

Dijital yerli (digital native) ve dijital göçmen (digital immigrant) kavramları etkileşim kurma biçimlerinin farklı olmasından dolayı, gelişen yeni ortamlara ayak uydurma ile doğrudan bağlantılıdır. Bu bağlamda bilginin ve bilgiye erişimin yeniden tanımlanmasının yön verdiği bireysel ve toplumsal tercihlerdeki değişimler, söz konusu iki kavramın doğru tanımlanmasında önem taşımaktadır. Gibson, Koontz ve Van Den Hende (2008) dijital ayrımın ve dijital yerli neslinin doğuşunun 1987 yılında gerçekleştiğini belirtmişlerdir. Beloit Koleji'nde (2009) gerçekleştirilen ve dijital yerli neslinin özelliklerinin listelendiği bir çalışmada, 80'li yılların sonunda dünyaya gelen neslin sesli e-postayı bilen ve oyun konsolları ile oynarken uyuyakalan bireyler oldukları ifade edilmektedir.

Dijital yerli ve dijital göçmen kavramlarını ortaya atan Marc Prensky, eğitimi gerek geçmişe gerekse geleceğe yönelik tekrar düşünmenin gerekliliğini ön plana çıkarmıştır. Prensky (2001) bugünün öğrencilerin son yıllarda radikal biçimde değiştiğini, öğrencilerin bilgisayarların, video oyunların ve internetin dijital dilini konuşan "yerli konuşmacılar" olduklarını ifade etmiştir. Öğretmen konumundaki kişilerin ise dijital dünyaya doğmamış olsalar da yaşamlarının belli dönemlerinde yeni teknolojilerden yararlandıklarına bu nedenle de "dijital göçmenler" olduklarına dikkat çekilmiştir. Bu bağlamda öğrenci, öğretmen ve sistem boyutunda paydaşları ele almanın uygun olacağ 1 vurgulanmıştır.

Günümüzün öğrencileri ve giderek yükselen sayıdaki öğretmenler dijital yerli olarak sistemde yer almakta ve sinıflarında da Web 2.0 teknolojilerini kullanmak istemektedirler (Palfrey ve Gasser, 2008). Web 2.0 araçlarını yakından takip eden dijital neslin bireyleri; podcasting kullanan, bloglarla ve sosyal etkileşim hizmetleriyle kendini ifade eden, dosya paylaşımı, sosyal paylaşım ve wikilerle farklı bir sosyalleşme şekli yaşayan bir topluluğu temsil etmektedir (Kennedy ve diğer., 2007). Bu yönleriyle birbirlerinden ayrılan dijital yerli ve dijital göçmenlerin farklı özelliklerinin olduğu anlaşılmaktadır.

Prensky (2001) tarafindan ifade edilen "dijital yerli" ve "dijital göçmen" kavramlarına Palfrey ve Gasser (2008) bir üçüncü grubu eklemiş ve bu kavramı "dijital göçebe" (digital settler) olarak ifade etmiştir. Dijital göçebeler, dijital yerli ve dijital göçmenlere göre daha yaşlı bireyleri ifade etmektedir. Dijital göçmenler ve dijital göçebeler, dijital yerlilerin zaten içinde bulunduğu dijital dünyaya sonradan gelen bireylerdir. Dijital 
göçmenler her ne kadar dijital dünyada doğmasalar da dijital göçebeler kadar dijital dünyaya uzak değillerdir sadece dijital dünyaya gelişimlerinin ileriki dönemlerinde gelmişlerdir. Oysaki dijital yerliler hep o dünyanın içindedirler ve analog dünya ile hiç tanışmamışlardır. Bu üç kavram Şekil 1' deki gibi ifade edilmeye çalışılmıştır.

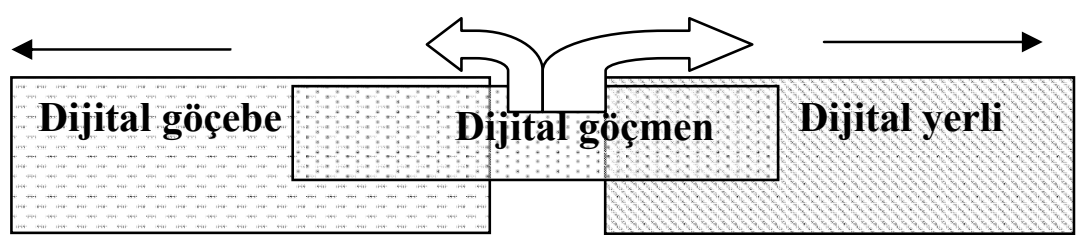

Şekil 1. Dijital yerli, dijital göçmen ve dijital göçebe

Şekil 1'den de anlaşıldığ üzere Prensky (2001) tarafından ifade edilen dijital göçmenleri Palfrey ve Gasser (2008) yetişkin ve yaşlı göçmenler olarak ifade etmiş, yetişkin bireyleri dijital göçmen ve yaşlı bireyleri dijital göçebe olarak tanımlamıştır. Dijital yerli ve dijital göçebe arasında bir köprü oluşturan ve her iki neslin özelliklerini bir miktar barındıran dijital göçmenlerin, dijital yerli ve dijital göçebe arasındaki büyük farklılıktan bu yönüyle ayrıldığı görülmektedir. Dijital göçebe kavramının uluslararası alanyazında "digital settler" kavramıyla ifade edildiği görülmektedir (Palfrey ve Gasser, 2008). "Digital settler" kavramının Türkçe karşılığının "yeni bir yere yerleşen kimse" olduğu ve ulusal alanyazında ilk kez Odabaşı (2009) tarafindan "dijital göçebe" olarak ifade edildiği görülmektedir.

Palfrey ve Gasser (2008)'e göre dijital göçmenler analog dünyada doğan ancak dijital kültür ile de şekillenen nesli oluşturmaktadır. Dijital göçebeler ise analog dünyada doğan ve yetişen dijital dünyaya sonradan uyum sağlamaya çalışan nesli oluşturmaktadır. Dijital göçebeler, dijital yerlilerin ve dijital göçmenlerin aksine ağırlıklı olarak geleneksel ve analog yapıya bağlı kalmaya devam etmektedirler. Dijital göçmenler, dijital göçebelere göre daha çabuk dijital dünyaya uyum sağlamaktadırlar.

Dijital göçmenler, kimi zaman çocuğu ile aynı dili konuşmak onu daha iyi anlamak isteyen ebeveynleri, kimi zaman ise en az dijital yerli öğrenciler kadar teknoloji kullanmak durumunda olan öğretmenleri de ifade etmektedir. Dijital göçmenler arasında; dijital dünyayı sevdiği ve istediği için takip eden bireylerin yanında dijital dünyayı işi ya da mesleği gereği takip etmek ve kullanmak zorunda olan ögretmenler, akademisyenler, mühendisler vb. iş alanlarında görev yapan bireylerin yer aldığı söylenebilir. Dijital göçmenler, teknoloji bilgisine ve teknoloji kullanımına ne dijital yerliler kadar sahip ne de dijital göçebeler kadar uzaktırlar. Peters (1999), dijital göçmenlerin bir 
anlamda postmodernist düşüncenin bir kahramanı olduğundan söz etmektedir. Öte yandan özellikle mobil teknolojilerin gelişimi ile bireylerin sosyal ağlara bağlanma biçimlerinin değiştiği göz önüne alındığında, dijital göçmen kavramına da dijital yerli ve dijital göçebe kavramlarında olduğu gibi metaforik bir bakış açısıyla yaklaşılabileceği söylenebilir.

\section{Dijital Yerli, Dijital Göçmen ve Dijital Göçebe Özellikleri}

Günümüzde dijital yerlilerin nasıl öğrendiğinin ve öğrenmedeki tercihlerinin neler olduğunun anlaşılması eğitim sürecine önemli katkılar getirebilecektir. Dijital yerli olan öğrenciler ve genellikle dijital göçmen olan öğretmenler arasında özellikle sınıf ortamında iletişim, etkileşim, birbirini anlama gibi alanlarda birtakım problemler yaşanabilmektedir. $\mathrm{Bu}$ problemlerin kaynaklarından birinin, öğretmen ve öğrencilerin farklı eğitim sistemlerinden yetişmeleri olduğu söylenebilir. Bu bağlamda öğretmenlerin öğrencileri, öğrencilerin de öğretmenleri olumsuz biçimde eleştirdiği birtakım istenmeyen durumların yaşanması karşılıklı bir anlaşmazlığın sonucu olarak göze çarpmaktadır. Bu duruma örnek olarak geleneksel sınıf ortamlarında öğrencilerin dijital yerlileri, öğretmenlerin ise dijital göçmenleri temsil etmesi gösterilebilir (Naish, 2008; Weiß ve Bader, 2010).

Dijital yerlilerin bilişim teknolojilerini kullanarak farklı bilgi ve becerilere daha kolay sahip oldukları söylenebilir. $\mathrm{Bu}$ nedenle dijital yerlilerin önceki neslin öğrenme tercih ve stillerinden daha farklı tercih ve stillere sahip oldukları düşünülmektedir (Bennett, Maton ve Kervin, 2008; Dede, 2005). Dijital yerliler teknolojiyi öğrenme etkinliklerinde ve sosyal çevreleriyle iletişim kurmada kullanmaktadırlar (Lei, 2009). Dijital yerliler kolayca yeni teknolojilere uyum sağlar ve onu kullanırken bozmaktan ya da yanlış yapmaktan korkmazlar çünkü daha çabuk öğrenirler (Bennett, Maton ve Kervin, 2008). Dijital göçmenler ve özellikle de dijital göçebeler teknolojiyi bozmaktan korkarken, dijital yerliler teknolojik aracın yeniden başlatılması ile her şeyin önceki haline dönebileceğini bilerek teknolojiyi daha korkusuzca kullanır (Günther, 2007; Rikhye, Cook, ve Berge, 2009).

Dijital yerliler için internet gibi dijital ortamlar sanal ortam olarak değil gerçek yaşamsal ortamlar gibi görülmektedir (Weltevrede, 2011). Dijital yerliler için dijital dünya doğal bir ortamken, dijital göçmenler için bu ortama teknoloji ile pratik yapılarak sonradan ulaşılmak istenir. Dijital göçebeler için ise dijital dünyada yaşamak hiç de kolay değildir ve dijital dünya onlar için çokta çekici değildir.

Roberts (2005) internet neslinin teknolojiden beklentilerini belirlemek için öncelikle teknolojiyi nasıl tanımladıklarını ortaya koymanın uygun 
olacağını belirtmiştir. Bu bağlamda "teknoloji sizin için ne ifade ediyor?" sorusuna verilen öğrenci yanıtlarını özetlemiştir:

Teknoloji bence işletim sistemime format atıp virüssüz, sinırsız, istediğim zaman istediğim şeyi yapacağım şekilde en son teknolojinin ürünü olan yazılımı Bill Gates'in kuralları olmadan kullanmaktır.

Geliştirilen bir programin günlük işlerimde bana yarar sağlamasıdır. Hava bültenini dijital ortamdan takip etme veya cep telefonundaki sistemin ben mesaj yazarken metin tahmini yapmast gibi.

İşlerimi daha hızlı yapmamı sağlayacak yazılım veya donanımların tümü, iyi bir kütüphaneden dijital arama yapmamı ve aynı anda üç kişiyle sohbet etmemi sağlayan arama paketi.

Yukarıda bir bölümü verilen yanıtlar araştırmacı tarafindan teknolojinin bilgisayar veya internetle sınırlı tutulmaması gerektiği, bilgiye, iletişime açı elektronik temelli uygulama veya araçlar bütünü olarak görülmesinin gerekli olduğu şeklinde yorumlanmıştır. Bunun yanı sıra teknolojinin internet neslinin değişmesini gerekli kılan bir unsur olarak değil, onların gereksinimlerine uyum sağlayarak gelişen bir unsur olarak ele alınmasının gerekliliği üzerinde durulmuştur.

İnternet neslinin nasıl öğrendiği üzerinde duran McNeely (2005), teknolojinin göze hoş görünen yenilikler açısından değerlendirilmekten çok öğrenme aracı olarak ele alınması gerektiğini belirtmiştir. Bunun yanı sıra öğrencilerin yeni çıkan bir yazılımı öğrenme konusunda kullanma kılavuzu yönlendirmelerinden çok, yazılımın deneme sürümü üzerinde yaparak yaşayarak öğrenme yaklaşımını tercih ettiklerine dikkat çekilmiştir. Özellikle bilişim teknolojilerinin öğrencileri izole eden bir yap1 olarak değil, tersine etkileşimli ortamlar sunan ve sosyalliğin yeniden düşünülmesini olanaklı kılan ortamlar olarak değerlendirilmesinin daha sağlıklı olacağı ifade edilmiştir. Öte yandan bilişim teknolojilerinin ağırlı̆̆ını arttırdığı bir ortamda öğrenme durumları içerisinde etiğe aykırı birtakım konuların da gündeme gelebileceği belirtilmiş, "kes-yapıştır kültürünün" öğrenme açısından iyi sonuçlar doğurmadığına ve bir öğrenme deneyimi olmadığına değinilmiştir.

Windham (2005), günümüzde öğrenci başarısının veya internet neslinin başarılı olarak nitelendirilmesinin sınıftaki etkinlikle sınırlı olmadığının altını çizmiştir. Bunun yanı sıra; öğretim programı dişında konu alanına ilişkin öğrenmeleri zenginleştirecek etkinliklerle, sosyal yapıyla yoğrulan ve liderlik özelliklerini geliştirmelerine destek veren uygulamalara artık daha 
sık rastlandığına dikkat çekmiştir. Prensky’nin (2004) ortaya koyduğu, dijital yerlilerin söz konusu özelliklerden süzülen davranış ve öğrenme farklılıkları aşağıdaki gibi özetlenebilir:

Dijital yerliler farklı şekilde iletişim kurarlar: Dijital yerliler, dünya ile iletişim kurarak kendi amaçlarına ulaşmada daha hızlı başarıya ulaşırlar. Dijital yerliler, e-posta, sohbet, haber ve tartışma grupları ile çevrimiçi ya da çevrimdışı birbirlerinden haberdardırlar.

Dijital yerliler farklı şekilde paylaşırlar: E-posta ve metinle etkileşim en bilinen paylaşım yollarıyken, dijital yerliler ayrıca blog türü platformlarla entelektüel becerilerini geliştirmektedirler. Bunlar dışında web kameraları ve cep telefonlarını çevresel araçlar olarak kullanmaktadırlar.

Dijital yerliler farklı ortamda alış-verişler yaparlar: Farklı web siteleri aracılığıyla bütün alış verişlerini yapan dijital yerliler vardır. Bir başka deyişle neredeyse bütün gereksinimlerini sanal ortamlardan sağlamaktadırlar.

Dijital yerliler ellerindekileri farklı biçimde değiştirirler: Müzik dosyalarını, videoları paylaşan dijital yerliler, ücretsiz olan bu paylaşımlarla yükleme ve indirmeye çok fazla vakit ayırmaktadırlar.

Dijital yerliler farkl yollarla sanal içerik oluştururlar: Dijital yerlilerin sadece web sayfaları ya da flash videoları değil aynı zamanda oyunlarında yarattıkları evleri, mobilyaları, giysileri kısacası kendi dünyaları da farklıdır.

Dijital yerliler farklı şekilde buluşurlar: Yüz yüze etkileşimden daha çok çevrimiçi buluşmaları tercih eden dijital yerliler, cep telefonlarındaki yazılımlar yardımıyla o an uygun olan rastgele belirledikleri kimselerle buluşabilirler.

Dijital yerliler farklı şeyler biriktirirler: Her ay yaklaşık iki milyar müzik dosyası indirip saklayan, dijital yerliler bu yönleriyle pul koleksiyonu yapan nesilden çarpıcı biçimde ayrılmaktadır.

Dijital yerliler farklı biçimde işbirliği içerisindedirler: Farklı rollere sahip olmaya istekli olan dijital yerliler, özellikle oyunlar yoluyla bir anlamda klanlar oluşturmuşlardır.

Dijital yerliler farklı biçimde değerlendirirler: Dijital yerliler internetteki oylamaları ve yorumları sayesinde görüşlerini etkili biçimde ortaya koyabilirler.

Dijital yerliler farklı biçimde öğrenirler: Geçmişte olmadığı kadar öğrenme kaynağına sahip olan dijital yerliler, öğretici konumundakilerin beceri ve bilgilerinin ötesinde sadece istediklerini öğrenmek konusunda israrcidirlar.

Dijital yerliler farklı biçimde araştırırlar: Bilgi yığınlarının bir konuyu araştırırken yarattı̆̆ yükten rahatsız olmayan dijital yerliler, e-postadan sonra en çok arama motorlarını kullanmaktadır. 
Dijital yerliler farkl biçimde analiz ederler: Basit bir ekran koruyucunun bilgisayarlarının işlemcisiyle bütünleşik çalışarak bilgilerini kopyalamasına aldırmayan dijital yerliler, farklı ilaç türlerinin etkileşimleri için rapor hazırlama konusunda da gönüllü olabilmektedir.

Dijital yerliler farkl biçimde ifade ederler: Dijital yerliler, bilgiyi edinir edinmez paylaşmayı ve sunmayı severler. Cep telefonlarını, video kameraları, blogları ve sosyal paylaşım ağlarını (facebook, twitter vb.) kendilerini ifade etmek için kullanırlar. Dijital yerliler sadece ortam ve kullandıkları araçlarla değil aynı zamanda kullandıkları dil ile de farklılık gösterirler. Kullandıkları dile ilişkin farklılığın temelinde kuşkusuz internet ve dijital ortam yatmaktadır. Bu kullanım sözcüklerdeki kısaltmalar ve cümle sonlarındaki özel simgeler de içermektedir (Çakır ve Topçu, 2005). Öyle ki dijital yerlilerin bu farklı dil kullanımını dijital göçmen ve dijital göçebeler anlamakta zorluk çekebilmektedir.

Dijital yerliler farklı biçimde programlarlar: Macromedia Flash gibi yazılımlar sayesinde dijital yerliler özellikle oyun benzeri uygulamalarda oldukça yetkin konuma gelmişlerdir.

Dijital yerliler farklı biçimde yetişirler: Ev, okul ve diğer fiziksel mekanlara çevrimiçi ortamların eklenmesiyle dijital yerlilerin yetişme biçimleri değişmiş, her bir mekanın sınırlarını doğru belirlemek önem kazanmıştır. Bir başka deyişle, dijital yerlilerin kendi çizdiği sınırların giderek daha görünmez olduğu günümüzde, özellikle davranış değişikliği bağlamında çocukluktan yetişkinliğe dikkatle izlenmeleri gerektiği göz önünde bulundurulmalıdır.

Dijital yerliler, yukarıda özetlenen özellikleri ile teknolojinin etkilediği yeni yaşam düzenine dijital göçmen ve dijital göçebelere göre daha hızlı uyum sağlamaktadır. Yeniliklere daha açık olan söz konusu grup, aynı zamanda dijital göçmenlerden ve dijital göçebelerden ayrılan özelliklerini davranışlarına yansıtma yönüyle de farklılaşmaktadır. Bu noktada dijital yerlilerin, her geçen gün güncellenen yaşam stilleri ve davranış kalıplarındaki değişimlerin dikkat çekici olduğunu söylemek olanaklıdır.

\section{Yaşam Stilleri ve Davranışların Değişimi}

Dijital yerliler, dijital göçmenler ve dijital göçebeler saç stili, kılık kıyafet, müzik seçimi gibi birçok konuda farklı yaşam tarzına ve davranış şekillerine sahiptirler (Prensky, 2001). Ancak asıl farklılığın teknoloji kullanımından ve teknolojiyi algılamadan kaynaklandığı söylenebilir. $\mathrm{Bu}$ nesiller arasında teknoloji açısından oluşan farklılık aile, sınıf ortamı gibi birçok alanda kendini gösterebilmektedir. Bu farkl1lık dijital yerliler ve dijital göçebeler arasında daha belirgin olarak ortaya çıkarken, dijital 
göçmenler her ne kadar dijital göçebelerin bazı özelliklerini taşısa da daha ileriye dönük bakabilmektedir. Bu durum, dijital göçmenlerin teknolojiyi takip edebilmelerini ve uyum sağlayabilmelerini kolaylaştırmaktadır. Gerek dijital yerliler gerekse dijital göçebeler kendi dünyalarında ve kendi stilleri ile daha başarılıdırlar. Örneğin bir baba ve oğlunun gerçek yaşamda oynadıkları futbol maçı baba lehine sonuçlanabilirken, bu durum bir bilgisayar oyununda oğlunun lehine dönebilmektedir. Her ne kadar dijital yerli, dijital göçmen ve dijital göçebeler birbirlerinden kesin çizgilerle ayrılmasa da ve bu durumu ölçebilecek kesin ölçümler bulunmasa da, her grubun taşıdağı bazı davranış ve özellikler bulunmaktadır. Alanyazında belirtilen yönleriyle ön plana çıkan dijital yerli, dijital göçmen ve dijital göçebe kavramları arasındaki farkl11ıklar Tablo 1'deki kavramlarla ilişkilendirilmiştir (Bayne ve Ross, 2007; Ben-David, 2011, Carrier ve diğer., 2009; Palfrey ve Gasser, 2008; Prensky, 2005; Prensky, 2009; Shah ve Jansen, 2011; Weiß ve Bader, 2010; Weltevrede, 2011).

Tablo 1. Dijital yerli, dijital göçmen ve dijital göçebe özellikleri

\begin{tabular}{lll}
\hline Dijital Yerli & Dijital Göçmen & Dijital Göçebe \\
\hline Öğrenci & Öğretmen & Öğretmen \\
Hızlı & Hızını duruma göre ayarlayan & Yavaş \\
Genç & Yetişkin & Yaşlı \\
Gelecek & Duruma uygun & Geçmiş \\
Çok sayıda çoklu görev & Az sayıda çoklu görev & Seri düşünme \\
(paralel düşünme) & & \\
Resim & Resim ve metin & Metin \\
Oyun & Bazen oyun, ağırlıklı olarak gerçek & Gerçek \\
İleriye dönük bakan & Daha çok ileriye dönük bakan & Geriye dönük bakan \\
Dijital & Dijital ve analog & Ağırlıklı analog ve geleneksel \\
Eylem & Eylemi bilgiyle yoğuran & Bilgi \\
Sürekli bağlantı & Gerektiği kadar bağlantı & Bağlantı izolasyonu \\
\hline
\end{tabular}

Tablo 1'de özetlenen özellikler incelendiğinde, dijital yerlilerin yeni teknolojilerden daha çok etkilenen ve etkin öğrenme yaklaşımlarına daha çok değer veren bireyler olarak ön plana çıktıkları görülmektedir. Üç grup arasındaki bu farklılıkların dijital yerli ve dijital göçebeler arasında daha çok belirgin olarak gözlendiği söylenebilir. Dijital göçmenlerin sözü edilen her iki neslin de içinde bulunması nedeniyle dijital ve analog dünyalar arasında geçişlerde daha kolay uyum sağlayabildikleri söylenebilir. Bilgisayar, internet, cep telefonu gibi teknolojilerle iç içe yaşayan dijital yerliler, teknolojinin topluma yayıldığı bir toplumda doğmaları nedeniyle önceki nesilden farklı birtakım davranış değişiklileriyle yetişmektedirler. Bunlar 
arasında; cep telefonunun hafizaya sahip olması nedeniyle telefon numarasını ezberlemeye ihtiyaç duymamaları, metinlerin sesli okunabilmesiyle kendisinin okumaya ihtiyaç duymaması yer almaktadır (Günther, 2007).

Endüstri çağının bireyleri olan dijital göçmenler ile dijital çağın bireyleri olan dijital yerliler arasındaki farklılaşma farklı biçimlerde ifade edilmiş̧ir (Brown, 2000; Frand, 2000; McMahon ve Pospisil, 2005; Oblinger ve Oblinger, 2005; Şahin, 2010). Bunlar:

Bilgisayarlar eski teknolojilerdir: Endüstri çağında telefon, televizyon ve otomobil teknoloji olarak görülmezken bilgisayar, internet, cep telefonu gibi araçlar teknoloji olarak görülmekteydi. Ancak dijital çağda bu teknolojilerin içinde doğan dijital yerliler için bilgisayar, internet gibi teknolojiler eski teknolojiler olarak görülmektedir. Dijital yerlilerin teknoloji kavramından iphone, ipad, dizüstü gibi yeni teknolojileri anladıkları söylenebilir.

Internet televizyondan daha iyidir: Endüstri çağında insanların saatlerini televizyon başında harcamaları dijital çağda yerini internete bırakmıştır.

Gerçeklik artık gerçek: Simülasyon, hologramlar gibi gerçeğe yakın resim ve animasyonların kullanıldığı ortamların gelişmesiyle sanal gerçeklik de artık gerçeğe yaklaşmıştır. Ayrıca gerçek olmayan kimliklerin de bu ortamların sunduğu olanaklarla gerçekle ayırt edilemez durumuna gelmesi gerçek ve gerçeklik arasındaki farkın kapanmasına yol açmıştır.

Bilmek yerine yapmak: Endüstri çağında bilginin ve teknolojinin birey ve kurumları etkilemesi daha yavaşken içinde bulunduğumuz dijital çağda hızlı gelişim gösteren teknolojiden ve bununla paralellik gösteren bilginin yayılmasından hızlı bir şekilde etkilenilmektedir. Endüstri çağında bilgi daha çok üretim için kullanılırken dijital çağda yapmak, uygulamak, etkileşmek ve eyleme dökmek için kullanılmaktadır.

Deneme-yanılma yoluyla öğrenme: Endüstri çağının bireyleri teknolojiyi kullanmadan önce sonuçlarını düşünüp deneme yolunu seçerken, dijital çağın bireyleri deneme-yanılma yoluyla, bozmaktan korkmadan teknolojiyi kullanmaktadır. Bu nedenle birçok kavram ve onun gereklerine de sahiptirler.

Çoklu görev: Dijital çağın bireyleri bir yandan ödev yaparken, bir yandan yemek yiyip, telefonda konuşup, internette gezinebilir. Bir başka deyişle aynı anda tek bir şeye yoğunlaşmamaktadırlar.

Bağll kalma: Dijital çağın bireyleri cep telefonu, bilgisayar, internet gibi teknolojileri kullanarak her zaman her yerde birbirleriyle sürekli iletişim halindedirler. 
Gecikmeye ilişkin tahammülsüzlük: Dijital çağın bireylerinin özellikle iletişim sırasında gecikmeye tahammüllerinin olmadığ görülmektedir. Telefon ile üç defadan fazla çağrıyı bekleyememe, gönderdiği e-postaya, mesaja ve çağrıya bir an önce yanıt almak isteme dijital çağın bireylerinin özelliklerindendir.

Yaratıcı ve kullanıcı arasında bulanıklık: Dijital araçların sunduğu olanaklarla video, ses ve metin gibi bilgi kaynaklarının kopyalanması daha fazla kolaylaşmakta ve dijital çağın bireyleri arasında oldukça sık kullanılmaktadır. $\mathrm{Bu}$ durum, bilginin asıl sahibi ile bilgiyi kullanan arasındaki farklılaşmayı azaltmaktadır.

Endüstriyel çağ ile dijital çağ arasındaki uçurum özellikle bilginin kullanılma amacının yeniden düşünülmesini gerekli kılmıştır. Yaşam stilleri ve davranışların da bir anlamda dijitalleştiği ve farklı düşünce yapıları ile bakış açılarının teknoloji doğrultusunda şekillendiği söylenebilir. Dijital çağın bireyleri için "daha yeni ise daha iyidir" anlayışı hüküm sürmekte iken dijital yerlilerdeki bu inanış, en yeni olanlarla çoklu etkileşim biçiminde yaşamın birçok alanına yansımıştır.

Alanyazın incelendiğinde dijital yerli ve dijital göçmenlere ilişkin özellikle öğrenci ve öğretmen boyutunda birçok çalışmaya rastlanmaktadır. $\mathrm{Bu}$ çalışmaların özellikle öğretmen adayları ve yükseköğretim öğrencileri üzerinde yoğunlaştığı görülmektedir.

Lei (2009) dijital yerli öğretmen adaylarına yönelik çalışmasında; öğretmen adaylarının günlük yaşamlarında teknolojiyi vazgeçilmez olarak gördükleri, günlük belirli bir süre özellikle sosyal ve iletişim amaçlı teknoloji kullandıkları, kullanımı daha zor ve ileri düzey teknolojileri kullanmada yetersiz olduklarını gözlemiştir. Bunlarla birlikte, öğretmen adaylarının teknolojinin sınıflarda kullanımına ilişkin olumlu tutuma sahip oldukları ancak bu teknolojilerin sinıflara entegrasyonu konusunda bilgi, beceri ve deneyim açısından yetersiz oldukları gözlenmiştir. Çalışmada öğretmen adaylarının teknolojiye tam olarak yetkin olmadıkları bu nedenle bu bireylerin tam olarak dijital yerli olmadıklarını vurgulanmıştır.

Kennedy ve arkadaşları (2008) yükseköğretim öğrencilerinin teknolojiye erişim, teknolojiyi kullanma ve teknolojiye ilişkin algılarını ölçmeye yönelik çalışmalarında yükseköğretim öğrencilerinin dijital yerli olup olmadıklarını incelemişlerdir. Çalışmada; yükseköğretim öğrencilerinin dijital yerli olmalarında bir homojenliğin olmadığı ve sınıflarda sayısal uçurumun söz konusu olduğu belirlenmiştir. Ayrıca öğrencilerin bazı teknolojileri her gün kullandıkları ancak her öğrenci için bu teknolojilerin eğitim amaçlı kullanılamadığını belirtmişlerdir.

Zimmerman ve Milligan (2008), yükseköğretim öğrencilerinin e-posta aracılı̆̆ıyla öğretim elemanı ile olan etkileşimlerini iki kategoriye ayırmış; e- 
posta metninde ayrıntıya girdiklerini düşünerek çekinen ve öğretim elemanının yazdıklarını bilmeye gereksinim duymadığını düşünen öğrencilerle, yazılı etkileşimde kendilerini pasif olarak görenlerin varlığına değinmişlerdir. Çalışmada, öğretim elemanı iletişim biçiminin öğrenciler tarafından nasıl algılandığına bağlı olduğu; öğrencilerin karşısındakinin yüzüne söyleyemeyeceklerini e-posta yoluyla ifade ettikleri ve öğretim elemanlarının formal bir dil kullanmayı tercih ettikleri belirtmiştir. Öte yandan McWhorter (2003), dijital göçmenlerin e-postayı mektup yazma gibi görmeye ve konuşur gibi e-posta yazmaya eğilimli olduklarına dikkat çekmiştir.

De Rosa, Cantrell, Hawk ve Wilson (2006), Ohio'da bulunan çevrimiçi bilgisayar kütüphanesi merkezinden yararlanan öğrencilerin kaynak tarama yöntemlerine yönelik bir çalışma yürütmüşlerdir. Kütüphanenin çevrimiçi olanaklarından yararlandıklarını bildiren öğrencilere sunulan anketlerden elde edilen veriler, öğrencilerin \%89 gibi önemli bir çoğunluğun webdeki arama motorlarından yararlandıkları ve yalnızca \%2'sinin kütüphanenin internet sitesi üzerinden arama yaptıklarını ortaya koymuştur. Öğrencilerin $\% 53$ 'ü arama motorları yardımıyla yapacakları aramanın, kütüphanede yapacakları bir arama kadar güvenilir olduğunu belirtmiş, \%16's1 ise kütüphaneye bilgi kaynağına erişimde daha az güvendiklerini ifade etmiştir. Araştırmanın sonuçları genel bir bakış açısıyla değerlendirildiğinde, öğrenci boyutunda çevrimiçi neslin, öğrenci profilini yeniden düşünme ve tanımlama açısından ağırlık kazanan grup olduğu söylenebilir.

McMahon ve Pospisil (2005) yaptıkları çalışmalarında öğrencilerin; \%66'sının teknolojiyle birlikteyken kendilerini rahat hissettiklerini, \%75'inin yeni teknolojilerin çıkmasını merakla beklediklerini, \%67'sinin aynı anda birden fazla işle (çoklu görev) meşgul olduklarını, \%67'sinin beklemekten hoşlanmadıklarını, \%99'unun derslerde en son teknolojilerin kullanılmasını istediklerini ve \%99'unun ise dizüstü bilgisayarlarının kendilerinin başarılı olmalarında önemli bir etken olduğunu belirlemişlerdir.

Alanyazındaki çalışmaların önemli bir bölümünün yükseköğretim öğrencilerine yönelik yapıldığı ancak ilköğretim ve ortaöğretim öğrencileri üzerinde yapılmış yeterli çalışmanın bulunmadığı görülmektedir. Oysaki dijital yerlilerin özellikle 1980'li yıllardan sonra doğan ve dijital kültürle etkileşen bireyleri kapsadığ 1 düşünüldügünde, 1990'l1 ve 2000'li yıllarda doğan bireylere yönelik de araştırmaların yapılmasına gereksinim olduğu görülmektedir. 


\section{TARTIȘMA VE SONUÇ}

Her ne kadar dijital yerliler teknoloji kullanımında dijital göçmenlere göre daha çok üstünlüğe sahip olsa da bugün dijital yerliler ile dijital göçmenler arasındaki farklılık geçtiğimiz yıllara göre daha da azalmış durumdadır. İçinde bulunduğumuz dijital çağda, bireyler teknolojiyi takip etmede yetersiz kalmakta ve bireylerin teknolojiyi kullanarak bilgiye ulaşması zorunlu hale gelmektedir. Bu duruma en iyi örnek oluşturan grup ise teknolojiyi daha çok işi, mesleği vb. nedenlerle takip etmek zorunda olan dijital göçmenlerdir.

Prensky (2001) ile başlayan dijital yerlilerin farklı öğrenme stilleri ve beyin yapılarına sahip olduğu varsayımı henüz deneysel çalışmalarla tam olarak desteklenmiş değildir. Ancak bu durumun belirlenmesi dijital yerlilerin eğiticileri ve dijital yerlilerin daha iyi anlaşılmaları açısından önem taşımaktadır (Rikhye, Cook ve Berge, 2009). İçinde bulunduğumuz dijital çağın bireyleri olan dijital yerli öğrencilerin eski yöntem ve tekniklerle eğitilmesinin yanlış olduğu söylenebilir. $\mathrm{Bu}$ durum, öğretmen ve öğrencilerin birbirini anlayamamasına, daha nitelikli bir eğitimin gerçekleşememesine neden olabilmektedir. Bu bağlamada aradaki farkın kapanması için öğretmenlerin birtakım eğitimlerle kendilerini geliştirmeleri özellikle sınıf ortamında teknolojiyle bütünleşik etkinliklilere yer vermeleri gerektiği söylenebilir.

Yapılan araştırmalar ve sonuçları doğrultusunda dijital yerlilerin yaşam stilleri ve öğrenme özelliklerinin bütünüyle anlaşılmış olduğunu söylemek olanaklı değildir. Özellikle bu konuya ilişkin araştırmaları yapan araştırmacıların çoğunun dijital göçmenler olduğu düşünüldüğünde, dijital yerlilerin olgulara ve çevrelerine verdikleri tepkileri anlamlandırmak güç görünmektedir. Öğretmenlerin, ebeveynlerin, ergenlerin ve yetişkinlerin teknoloji bağımlılığı, teknolojinin yanlış ve uzun süreli kullanımı konusunda yaşayabilecekleri problemlerin dijital yerlilik açısından yeniden ele alınarak değerlendirilmesi gerektiği düşünülmektedir. McNeely (2005) çalışmasında öğrencilerin teknolojiyi bir araç olarak görmeleri gerektiğini belirtmiştir. Ancak yeni neslin bireylerinin teknoloji ile iç içe yaşadığı ve yaşamlarının önemli bir bölümünde teknoloji araçlarını kullandıkları göz önünde bulundurulursa, dijital yerliler için teknolojinin bir araçtan çok daha fazla şey ifade ettiği söylenebilir. Bu bağlamda Prensky (2009) dijital yerli ve dijital göçmen kavramlarının yanında dijital bilgelik (digital wisdom) kavramını da ifade etmiştir. Prensky (2009) dijital araçların insan düşünce yapısını tahmin edilenden daha fazla etkileyebileceğini öne sürmüş, insanın doğuştan gelen yeteneklerini geliştirebilmesini ve bunun da ötesine geçmesini dijital bilgelik olarak adlandırmıştır. Benzer biçimde dijital 
gelişimin insan varlığ 1 için yaşamsal bir gerçek olduğu, dijital araçların hem bilişsel kapasitenin gelişiminde hem de sorunların çözümünde kullanılması gerektiğini belirtmiştir. Öte yandan bireylerin kendi başlarına ne kadar bilge olsalar da dijital teknolojiyi kullanmadan doğru karar veremeyeceklerine dikkat çekmiş ve gelecek için bireylerin dijital bilge olmalarının önemine vurgu yapmıştır. Dijital bilgelik kavramı ile dijital yerli, dijital göçmen ve dijital göçebe kavramları arasındaki sınırların da yok edildiği söylenebilir. Dijital göçmenlerin bazılarının dijital bilge olma durumları da söz konusudur. Ancak tüm bu olguların, sadece dijital göçmenlerin ve dijital göçebelerin teknolojiye ilişkin bakış açılarıyla değil aynı zamanda dijital yerlilerin de teknolojiyi nasıl algıladıkları ve teknolojiye yükledikleri anlamlar ile yeniden değerlendirilmesi gerekmektedir.

Alanyazın incelendiğinde özellikle yükseköğretim öğrencilerinin dijital yerli olma düzeyleri üzerine çalışmalar yapıldığı görülmektedir. $\mathrm{Bu}$ çalışmalarda yükseköğretim öğrencilerinin sadece bir kısmının dijital yerli oldukları, birçoğunun teknolojiyi kullanabildiği ancak öğretim ortamlarına entegre edemedikleri gözlenmiştir (Lei, 2009; Kennedy ve diğer., 2008; Kvavik, 2005; Şahin, 2010). Ortaya çıkan sonuca bağlı olarak her toplumun teknoloji gelişmişliği birbirinden farklılık gösterebileceği için bireylerin dijital yerli olma düzeyleri ve yaşlarının da toplumdan topluma farklılık gösterebileceği göz ardı edilmemelidir. Bu nedenle farklı yaş gruplarında daha çok çalışma yapılması gerektiği söylenebilir. $\mathrm{Bu}$ bağlamda derinlemesine bilgi edinmek için nitel araştırmaların desenlenmesine ihtiyaç duyulmaktadır.

Gibson, Koontz ve Van Den Hende (2008) ve Prensky (2001) gibi araştırmacıların ifade ettiği dijital yerlilerin 1980'li yıllarında doğdukları ve bu neslin dijital yerli olarak ifade edilmesi araştırmalarla tam olarak desteklenmemektedir. Bu neslin bireylerinin dijital yerli olma durumlarının olduğu ama her bireyde bütün dijital yerli özeliklerinin gözlenmediği söylenebilir. Bu nedenle dijital yerli bireylerinin yeniden tanımlanmasında ve 1990'lı yıllarda doğan bireyler üzerinde daha çok çalışma yapılmasında yarar bulunmaktadır. Ayrıca Prensky'nin (2001) dijital yerli kavramını ifade ettiği zamandan bugüne uzun bir süre geçtiği, bu nedenle dijital yerli ve dijital göçmen kavramlarının yeniden tanımlanmasına gereksinim olduğu söylenebilir. Sadece bu kavramların değil aynı zamanda dijital yerliler ile ilişkili öğrenme stilleri vb. olguların da yeniden gözden geçirilmesine dayalı araştırılmaların yapılması gerekmektedir (Dede, 2005).

Her ne kadar Prensky (2001) 1980 sonrasında doğanları dijital yerli, 1980 öncesinde doğanları ise dijital göçmen olarak tanımlasa da bu tanımın toplumdan topluma, bireyden bireye değişebileceği unutulmamalıdır. Her topluma teknolojinin ulaşması ve yaygınlaşması farklılık 
gösterebileceğinden bu kavramlara yönelik sinırlar değişebilmektedir. Ayrıca, aynı toplum içinde de dijital uçurumun var olabileceği düşünülürse, bazı bireylerin bu tanımların dışında kalabileceği söylenebilir. Dijital yerlilerden birçok noktada ayrılan dijital göçmen ve dijital göçebeler için de yaş tanımı yapmak çok kolay görünmemektedir. Ancak alanyazında buna ilişkin bazı çalışmalara rastlanmaktadır. Lee ve Delli Carpini (2010) üç nesile yönelik yaptıkları çalışmada; dijital yerlileri 18-29, dijital göçmenleri 30-64 ve dijital göçebeleri ise 65 ve sonrası yaş aralığında tanımlamıştır.

Prensky (2001)'e göre 1980 öncesi doğanlar dijital göçmenler olarak ifade edilse de Palfrey ve Gasser (2008) daha yeni göçmenleri dijital göçmenler olarak tanımlamıştır. Bu bağlamda, yaşlı bireyler arasında dijital dünyaya uyumu nedeniyle dijital göçmenler olabileceği gibi, yetişkin bireyler arasında da dijital dünyadan oldukça uzak dijital göçebelerin varlı̆̆g söz konusu olabilir. Ancak bu durumun dijital yerli ve dijital göçmen, dijital yerli ve dijital göçebe arasında yaşanması çok olası değildir. Dijital yerlilerin dijital kültür içinde doğmaları ve analog dünya ile hiç tanışmamış olmaları, dijital yerlilerin birçok duruma ilişkin farklı yaklaşım ve düşüncede olmaları kanısını oluşturmaktadır. Ancak tüm bu tanım ve sınıflamaların teknolojinin ulaştı̆̆ toplumlarda geçerli olabileceği ve teknoloji ile hiç tanışmayan toplumların bu bağlamda ayrı tutulması gerektiği unutulmamalıdır.

Gelecek merkezli eğitim kurgusu açısından yenidünya düzeni, bilgiyi etkili biçimde işleyen bireyler yetiştirmeyi önemli hale getirmiştir. Öğrencilerin teknolojiden olduğu kadar, var olan teknolojilerin öğrenme süreçlerinde işe koşulması şeklinde üniversitelerden de birtakım beklentileri bulunmaktadır. Öyle ki "okul bana bir şey vermedi, ne öğrendiysem oyunlardan öğrendim” (Prensky, 2005) diyen bir nesli eğitmek şüphesiz birtakım geleneklerden sıyrılmayı gerekli kılmaktadır. 


\section{KAYNAKLAR}

Bayne S., ve Ross J. (2007). The 'digital native' and 'digital immigrant': A dangerous opposition. Paper presented at the Annual Conference of the Society for Research into Higher Education (SRHE) December 2007.

Beloit Koleji. (2009). Anlayış listesi 2009. Aralık 09, 2010 tarihinde http://www. beloit.edu/ pubaff/mindset/2009.php adresinden alınmıştır.

Ben-David, A. (2011). Digital natives and the return of the local cause. In N. Shah \& F. Jansen (Eds.) Digital alternatives with a cause? book two: To think (pp. 10-23). The Hague: Centre for Internet and Society and Hivos.

Bennett, S., Maton, K. ve Kervin, L. (2008). The 'digital natives' debate: a critical review of the evidence. British Journal of Educational Technology, 39(5), 775786.

Brown, J. (2000). Growing up digital: How the web changes work, education, and the way people learn. Journal of the United States Distance Learning Association, 16(2), 31-36.

Büyüktanır, D., Duke, C., Karasar, N., Tileylioğlu, A. ve Toth, J.(2006). Türkiye'nin Başarısı İçin İtici Güç: Hayat Boyu Öğrenme Politika Belgesi. Mesleki Eğitim ve Ögrretim Sisteminin Güçlendirilmesi Projesi (MEGEP), 88.

Carrier, L.M., Cheever, N.A., Rosen, L.D., Benitez, S., ve Chang, J. (2009). Multitasking across generations: Multitasking choices and difficulty ratings in three generations of Americans. Computers in Human Behavior, 25(2), 483489.

Coyle, K. (2007). Managing technology: Digital divide. The Journal of Academic Librarianship, 33(6), 708-709.

Çakır, H. ve Topçu, H. (2005). Bir iletişim dili olarak İnternet. Sosyal Bilimler Enstitüsü Dergisi, 19, 71-96.

De Rosa, C., Cantrell, J., Hawk, J. ve Wilson, A. (2006). The 2003 OCLC environmental scan: Pattern recognition. Ohio Çevrimiçi Bilgisayar Kütüphanesi Merkezi. 8 Aralık 2010 tarihinde http://www.oclc.org/reports/ escan/default.htm adresinden alınmıştır.

Dede, C. (2005). Planning for neomillennial learning styles. Educause Quarterly, $28(1), 7-12$.

Dosaj, A. ve Jukes, I. (2006). Understanding digital children: In teaching \& learning in the new digital landscape. 20 Ekim 2008 tarihinde http://edorigami.wikispaces.com/file/view/Jukes+Understanding+ Digital+Kids.pdf adresinden edinilmiştir.

Frand, J. L. (2000). The information-age mindset: Changes in students and implications for higher education. Educause Review, 35(5), 14-24.

Gibson, T.L., Koontz, D.A. ve Van Den Hende, M. (2008). The digital generation: Teaching to a population that speaks an entirely new language. 8 Aralık 2010 tarihinde http://david.koontz.name/digital/Presentation_files/THE_DIGITAL_ GENERATION.pdf adresinden alınmıştır.

Goldfarb, A. ve Prince, J. (2008). Internet adoption and usage patterns are different: Implications for the digital divide. Information Economics and Policy, 20,2-15. 
Günther, J. (2007). Digital natives and digital immigrants. Hamburg: Studienverlag

Hassani, S. N. (2006). Locating digital divides at home, work, and everywhere else. Poetics, 34, 250-272.

Helsper, E. ve Livingstone, S. (2007). Gradations in digital inclusion: Children, young people and the digital divide. New Media \& Society, 9(4), 671-696.

Huang, H., Keser, C., Leland, J. ve Shachat, J.(2003). Trust, the Internet, and the digital divide. IBM Systems Journal, 42(3), 507-518.

Kennedy, G. E., Judd, T. S., Churchward, A., Gray, K. ve Krause K-L. (2008). First year students' experiences with technology: Are they really digital natives? Australasian Journal of Educational Technology, 24(1), 108-122.

Kennedy, G., Dalgarno, B., Gray, K., Judd, T., Waycott, J., Bennett, S., Maton, K., Krause, K-L., Bishop, A., Chang, R., ve Churchward, A. (2007). The net generation are not big users of web 2.0 technologies: Preliminary findings. Proceedings Ascilite Singapore, 517-25.

Kvavik, R. B. (2005). Convenience, communications, and control: How students use technology. In D. Oblinger ve J. Oblinger (Eds.) Educating the net generation (pp. 7.1-7.20). Boulder, CO: EDUCAUSE.

Lane, C. ve Yamashiro, G. (2008). Assessing learning and scholarly technologies: Lessons from an institutional survey. Educause Quarterly, 31(3), 1-8.

Lee, A. M., ve Delli Carpini, M. X. (2010, April). News consumption revisited: Examining the power of habits in the 21 st century. Paper presented at the $11^{\text {th }}$ International Symposium on Online Journalism, Austin, TX.

Lei, J. (2009). Digital natives as preservice teachers: What technology preparation is needed?. Journal of Computing in Teacher Education, 25(3), 87-97.

McCrindle, M. (2006). New generations at work: Attracting, recruiting, retraining \& training generation $Y$. McCrindle Research, 2 Ocak 2011 tarihinde http://www.mav.asn.au/CA256C320013CB4B/Lookup/NewGenerationsAtWork/\$file/NewGenerat ionsAtWork.pdf adresinden alınmıştır.

McMahon, M., ve Pospisil, R. (2005). Laptops for a digital lifestyle: Millennial students and wireless mobile technologies. Proceedings of ASCILITE 2005.

McWhorter, J. (2003). Doing our own thing: The degradation of language and music and why we should, like, care. New York: Gotham Books.

Monereo, C. (2004). The virtual construction of the mind: The role of educational psychology. Interactive Educational Multimedia, 9, 32-47.

Naish, R. (2008). The digital ages of man. E-learning Age, ABI/FORM Global, 1011.

Oblinger, D. ve Oblinger, J. (2005). Is it age or it: First steps toward understanding the net generation. 2 Ocak 2011 tarihinde http://www.educause.edu/ educatingthenetgen adresinden alınmıştır.

Odabaşı, F. H. (2009). 21. yüzyıl öğreneni (Davetli konuşmacı), 25. Yıl Etkinlikleri: AR-GE Konferans1, 14 Mart 2009, Ankara: Özel Ar1 Okullar1.

Palfrey, J. ve Gasser, U. (2008). Born digital: Understanding the first generation of digital natives. NY: Basic Books. 
Pedró, F. (2006). The new millennium learners: Challenging our views on ICT and learning OECD-CERI http://www.oecd.org/dataoecd/1/1/38358359.pdf, internet adresinden 02.01.2011 tarihinde edinilmiştir.

Peters, J. D. (1999). Exile, nomadism, and diaspora: The stakes of mobility in the western canon. New York: Routledge. http://books.google.com.tr/books?id=YmcdoGx YsrYC\&pg=RA1-PA17\&lpg=RA1-PA17\&dq adresinden 29 Aralı 2011 tarihinde edinilmiştir.

Prensky, M. (2009). Homosapiens digital: From digital immigrants and digital natives to digital wisdom. Innovate, 5(3).

Prensky, M. (2005). Listen to the natives. Learning in the Digital Age, 63(4), 8-13.

Prensky, M. (2004). The emerging online life of the digital native: What they do differently because of technology, and how they do it. 3 Aralık 2010 tarihinde http://www.marcprensky.com/writing/Prensky-

The_Emerging_Online_Life_of_the_Digital_Native-03.pdf adresinden alınmıştır.

Prensky, M. (2001). Digital natives, digital immigrants. On the Horizon, 9(5), 1-5.

Prieger, J.E. ve Hu, W. (2008). The broadband digital divide and the nexus of race, competition and quality. Information Economics and Policy, 20(2), 150-167.

Rikhye, R., Cook, S. ve Berge, Z. L. (2009). Digital natives vs. digital immigrants: Myth or reality?. International Journal of Instructional Technology and Distance Learning, 6(2), 3-11.

Roberts, G. (2005). Technology and learning expectations of the net generation. 2 Ocak 2011 tarihinde http://www.educause.edu/educatingthenetgen adresinden alınmıştır.

Shah, N. ve Jansen, F. (2011). Introduction. In N. Shah \& F. Jansen (Eds.) Digital alternatives with a cause? book two: To think (pp. 8-9). The Hague: Centre for Internet and Society and Hivos.

Şahin, M. C. (2010). Eğitim Fakültesi Öğrencilerinin Yeni Bin Yılın Öğrencileri Ölçütlerine Göre Değerlendirilmesi. Yayınlanmamış Doktora Tezi, Anadolu Üniversitesi Eğitim Bilimleri Enstitüsü, Eskişehir.

Weiß, S. ve Bader, H. J. (2010). How to improve media literacy and media skills of secondary school teachers in order to prepare them for the next generation of learners: A new type of in-service training for teachers. In M. Ebner \& M. Schiefner (Eds.), Looking toward the future of technology-enhanced education: ubiquitous learning and the digital native (pp. 37-54). Hershey. PA: Information Science Reference.

Weltevrede, E. (2011). Digital methods to study digital natives with a cause. In N. Shah \& F. Jansen (Eds.), Digital alternatives with a cause? book one: To be (pp. 10-23). The Hague: Centre for Internet and Society and Hivos.

Windham, C. (2005). The student's perspective. 2 Ocak 2011 tarihinde http://www.educause.edu/educatingthenetgen adresinden alınmıştır.

Zimmerman, L. ve Milligan, A. T. (2008). Perspectives on communicating with the net generation. Innovate Journal of Online Education, 4(2). 8 Aralık 2010 tarihinde http://innovateonline.info/pdf/vol4_issue2/Perspectives_on_Communicating_with_ the_Net_Generation.pdf adresinden alınmıştır. 